\title{
The Relationship between Hypomineralized Second Primary Molars and Molar Incisor Hypomineralization in a Group of School-Aged Children in Turkey
}

\author{
Esra Karakaya ${ }^{1, \odot}$ Hayriye Sonmez ${ }^{2}$ \\ 1 Pediatric Dentist, Waterloo, Ontario, Canada \\ ${ }^{2}$ Department of Pediatric Dentistry, Faculty of Dentistry, Altinbas \\ University, Istanbul, Turkey
}

\author{
Address for correspondence Esra Karakaya, MSD, 608 Columbia \\ Forest Blvrd N2V2K8, Waterloo, Ontario, Canada \\ (e-mail: ekanada2020@gmail.com).
}

Eur J Gen Dent 2021;10:65-72.

\begin{abstract}
Keywords

- molar incisor

hypomineralization

- deciduous molar

hypomineralization

- developmental

enamel defects

Objective This study aims to evaluate the relationship between hypomineralized second primary molars (HSPMs) and molar incisor hypomineralization (MIH) and to determine the prevalence of HSPM in different severities of MIH.

Materials and Methods The study included a total of 345 children aged 7 to 11 , affected with MIH at various severities. Scoring for HSPM defects was adapted according to the European Academy of Pediatric Dentistry diagnostic criteria and applied by a single calibrated examiner. Comparative evaluation of HSPM at various MIH severities was tested using a single variable logistic regression analysis. An odds ratio at a $95 \%$ confidence interval was used to test the relation between HSPM and MIH.

Results The prevalence of HSPM was $61.7 \%$ in MIH-affected children, whereas it was $2.6 \%$ in the control group $(p<0.001)$. The presence of HSPM and the increase in the number of affected teeth significantly raised the odds of the occurrence of MIH. HSPM prevalence was higher in children affected with milder MIH compared to those affected severely. The recorded defects were common as white-cream demarcated opacities without any loss of structure.

Conclusion The prevalence of HSPM was significantly higher in children presenting $\mathrm{MIH}$. Therefore, hypomineralization on the primary second molars pointed to an association between MIH and HSPM. For an early diagnosis of MIH, children presenting HSPM whose first permanent molars have not erupted yet should be followed up at regular intervals by pediatric dentists.
\end{abstract}

\section{Introduction}

Defects occurring from the irreversible damage of abnormalities caused by environmental factors during amelogenesis are identified as developmental enamel defects. ${ }^{1,2}$

Molar incisor hypomineralization (MIH), which is thought to be of systemic origin, found particularly in developmental enamel defects, for that it affects one or more permanent

DOI https://doi.org/ $10.1055 / \mathrm{s}-0041-1732951$ ISSN 2320-4753 first molars (PFM) with demarcated opacities, often seen in upper and lower incisors. ${ }^{3-8}$

The appearance of MIH defects varies from white-cream to yellow-brown. ${ }^{8-10}$ The severity of defects and enamel porosity develops as the color gets darker. ${ }^{11-13}$ Following mastication forces enamel porosity in PFM increases concomitantly with the loss of inorganic structure in severe opacities that leads to a decrease in mechanical strength and enamel loss. ${ }^{14-16}$

(c) 2021. European Journal of General Dentistry.

This is an open access article published by Thieme under the terms of the Creative Commons Attribution-NonDerivative-NonCommercial-License, permitting copying and reproduction so long as the original work is given appropriate credit. Contents may not be used for commercial purposes, or adapted, remixed, transformed or built upon. (https://creativecommons.org/licenses/by-nc-nd/4.0/).

Thieme Medical and Scientific Publishers Pvt. Ltd. A-12, 2nd Floor, Sector 2, Noida-201301 UP, India 
This structure loss is identified as posteruptive breakdown (PEB) according to the European Academy of Pediatric Dentistry (EAPD) criteria. ${ }^{17}, 18$ which can be seen with or without PEB. ${ }^{6}$

Similar to PFM, MIH defects may be present in primary second molars (psm), permanent second molars, premolars, and canine cusps. ${ }^{6,19-24}$ The development phase of psm and PFM is concurrent; however, the maturation phase is longer for PFM compared with psm. The localization and similarity of developmental phases may ease the occurrence of hypomineralization in these teeth in case of a risk factor came across during this time..$^{20,24-28}$ Thus, it was previously suggested that the presence of deciduous molar hypomineralization (hypomineralized second primary molars [HSPM]) may suggest a possibility of MIH occurrence in the future. ${ }^{20}$ Therefore, HSPM can be an indicator which can be used for the early diagnosis of $\mathrm{MIH}$ allowing clinicians to perform prophylactic treatments after the eruption of PFM. ${ }^{24}$

Even though there are studies performed on the prevalence of $\mathrm{MIH},{ }^{29,30}$ etiologic factors of $\mathrm{MIH},{ }^{31}$ and the effects of dioxins on the prevalence of $\mathrm{MIH}^{32}$ there is a lack of knowledge in the literature about the association, prevalence, and clinical presentation of HSPM in MIH cases. ${ }^{19,20,28}$ The risk markers and etiological factors should be classified precisely for an early identification of $\mathrm{MIH}$ and to preserve and initiate early management protocol. ${ }^{24}$

This study aims to assess the relationship between the two entities based on hypomineralization findings in psm with the following additional objectives:

- to determine the HSPM rates in MIH cases presented in different severities,

- to report prevalence, defect characteristics, and distribution of HSPM and MIH in school-aged children, and

- to compare defect characteristics in relation to the defect type among HSPM and PFM (i.e., creamy white opacity/yellowish brown opacity/PEB; extent, distribution, and location of defects individually).

\section{Materials and Methods}

This study was approved by the Ethics Committee of Ankara University Faculty of Dentistry with approval number of 14/9.

A total of 345 children aged between 7 and 11 years, was referred to the Department of Pediatric Dentistry, Ankara University, Faculty of Dentistry, due to their dental concerns. Patients presented with MIH $(n=115)$ in at least one PFMs without any systemic disorders were included in the study group. To not exclude any patients presenting $\mathrm{MIH}$, we aimed to reach minimum $100 \mathrm{MIH}+$ patients. Also, for the results to reflect clinical conditions, we arranged two control patients for every MIH patient according to the allocation ratio of $1: 2$. Therefore, considering the potential for patient care clinic, exclusion criteria, and patient consents we included $115 \mathrm{MIH}+$ and 230 healthy control subjects in our study. Considering our results (presented in - Table 1 ) and post hoc power analysis, the power of this study is 0.825 to 0.999 .

Children and their parents were informed in detail and informed consents were obtained. Children with hypomineralization only present on incisors, have defect smaller than $2 \mathrm{~mm}$, or without psm were excluded. HSPM defects of the children in the control group were assessed based on the same principles as it was performed in the study group.

\section{Intraoral Examination}

Children in the study group were examined using a probe and dental mirror under visual light. The teeth were not dried; however, children with a poor oral hygiene were examined following brushing. Diagnostic criteria for scoring MIH defects on PFM were adapted from the EAPD and used to score hypomineralization defects on both PFM and psm. ${ }^{19,26,33,34}$ A periodontal probe was used for the defect measurement and defects under $2 \mathrm{~mm}$ were excluded from the study. The severity of the MIH was determined based on Mittal and Sharma ${ }^{24}$ as following:

Mild MIH: White-cream opacities without PEB ( - Fig. 1)

Moderate MIH: Yellow-brown opacities without PEB (-Fig. 2).

Table 1 Presence of HSPM and the effects of the number of teeth with HSPM on MIH

\begin{tabular}{|c|c|c|c|c|}
\hline Variables & $\begin{array}{l}\text { Control group } \\
(N=230)\end{array}$ & $\begin{array}{l}\text { MIH group } \\
(N=115)\end{array}$ & $p$ & $\begin{array}{l}\text { Odds ratio } \\
\text { ( } 95 \% \text { confidence interval) }\end{array}$ \\
\hline \multicolumn{5}{|l|}{ HSPM } \\
\hline Negative & 224 (97.4\%) & $44(38.3 \%)$ & - & 1.000 \\
\hline Positive & $6(2.6 \%)$ & $71(61.7 \%)$ & $<0.001^{\mathrm{a}}$ & $60.242(24.646-147.250)$ \\
\hline $\begin{array}{l}\text { Median of the number of teeth with } \\
\text { HSPM }\end{array}$ & $0(0-4)$ & $3(0-4)$ & $<0.001^{\mathrm{a}}$ & $3.558(2.613-4.846)$ \\
\hline \multicolumn{5}{|l|}{$\begin{array}{l}\text { Distribution of the number of teeth } \\
\text { with HSPM }\end{array}$} \\
\hline Negative & 224 (97.4\%) & $44(38.3 \%)$ & - & 1.000 \\
\hline $1-2$ & $3(1.3 \%)$ & $4(3.5 \%)$ & $0.014^{\mathrm{a}}$ & $6.788(1.468-31.393)$ \\
\hline $3-4$ & $3(1.3 \%)$ & $67(58.2 \%)$ & $<0.001^{\mathrm{a}}$ & $113.697(34.212-377.845)$ \\
\hline
\end{tabular}

Abbreviations: HSPM, hypomineralized second primary molars; MIH, molar incisor hypomineralization. aStatistically significant $(p<0.05)$. 
Severe MIH: White-cream or yellow-brown opacities including enamel fracture/atypical restoration/tooth extraction (-Fig. 3).

The psm examination for hypomineralization was based on the 2003 EAPD criteria and the defined severity of MIH on the PFM was scored from the most severe. The criteria for atypical caries was also included from EAPD in addition to the criteria for atypical restoration. ${ }^{26,34}$ Children with a HPSM present tooth were classified as HSPM positive. Psm teeth were assessed as follows: the most affected tooth, distribution of the opacity (white-cream, yellow-brown), loss of tooth structure following tooth eruption, atypical restoration, and presence of psm extraction due to atypical caries

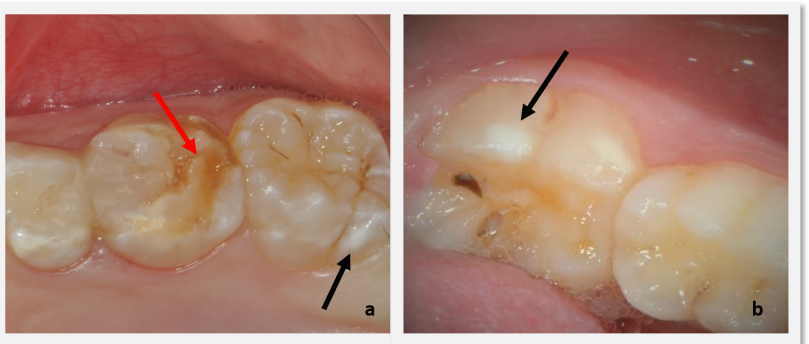

Fig. 1 Examples of mild MIH defects. (A) Black arrow shows whitecream opacities without a PEB on an upper PFM, the red arrow shows HSPM with a cream-brown opacity. (B) Black arrow shows whitecream opacity without PEB on a lower PFM. or MIH. Children not having a psm tooth were excluded from the study. Children with at least one HSPM but was extracted were recorded as "extraction due to HSPM."

Twenty-five participants were examined by a single calibrated examiner, and to evaluate the reproducibility and ensure consistency, same examination was conducted the following week. The examination findings were the same in $92.9 \%$ of the children with defects which implies the reproducibility of examinations and a high level of consistency (kappa: 0.96).

\section{Statistical Analysis}

Data were analyzed by using IBM SPSS Statistics 17.0 (IBM Corporation, Armonk, New York, United States). To assess the association between the severity of MIH on HSPM, single variable logistic regression analysis was used. Moreover, odds ratio (OR) and 95\% confidence intervals were calculated. The presence of HSPM, the effects of numbers of teeth having HSPM on MIH development, and the relationship between HSPM presence and severity of MIH were assessed using single variable logistic regression analysis. Furthermore, OR and 95\% confidence intervals were calculated for each variable. A $p$-value of $<0.05$ was set as the significant level for all tests.
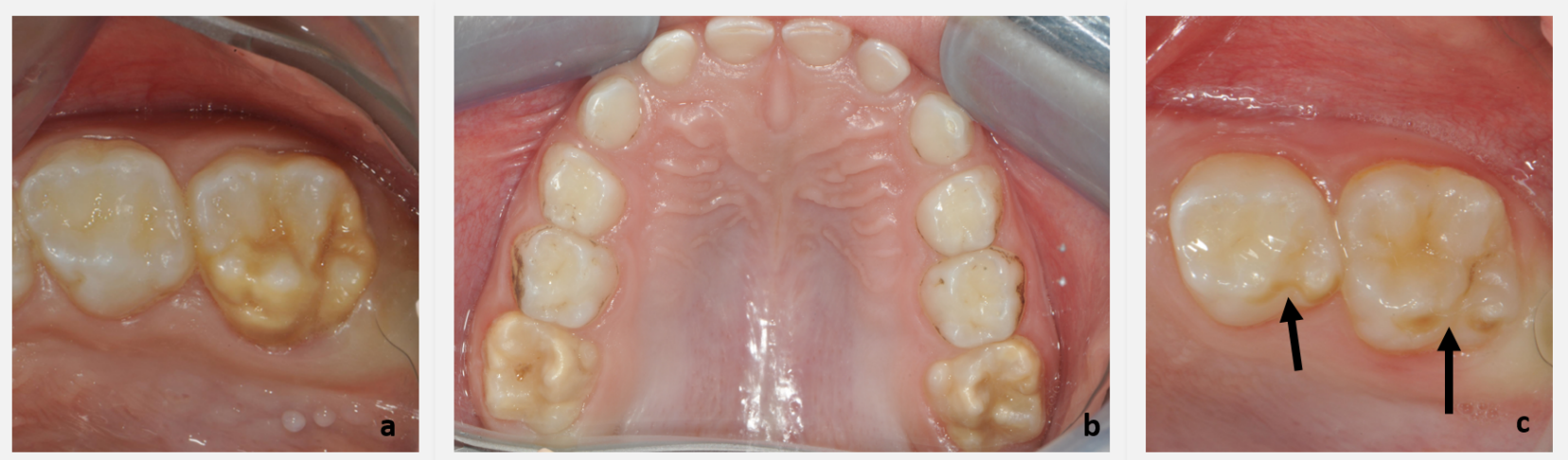

Fig. 2 (A, B) Examples of moderate MIH defects on upper PFMs. (C) The black arrows show yellow-brown opacities without PEB on upper PFM and upper psm.
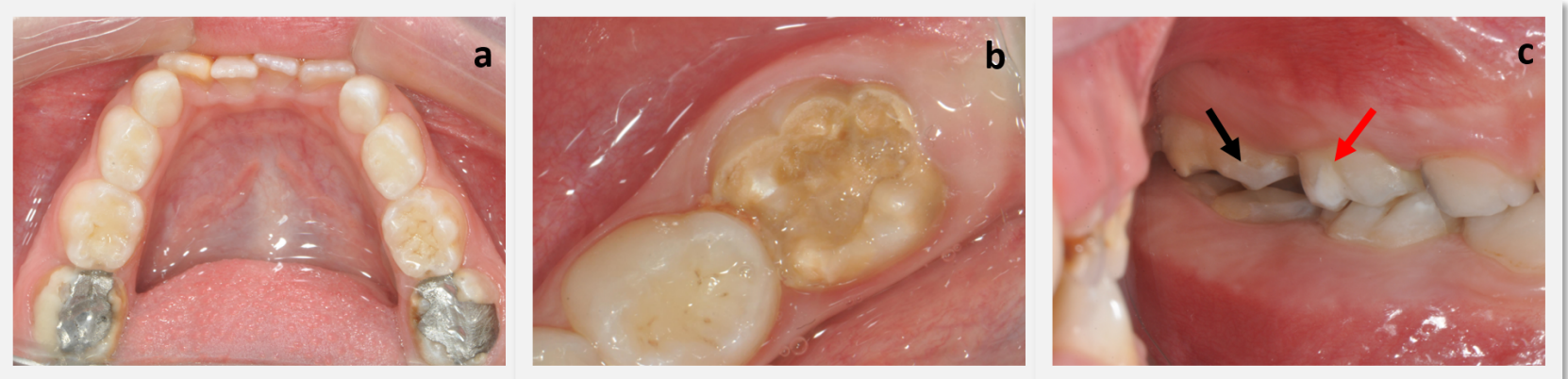

Fig. 3 Examples of severe MIH defects. (A) Yellow-brown opacities on lower PFMs with atypic amalgam restorations. (B) Yellow-brown opacity on a lower PFM including PEB. (C) Black arrow shows a severe MIH defect with an atypic restoration which extends to the buccal surface of the upper PFM, red arrow shows HSPM with a white-cream opacity on the buccal surface of an upper psm. 
Table 2 Clinical characteristics of study and control groups

\begin{tabular}{|c|c|c|c|}
\hline Variables & Control group $(N=230)$ & Study group $(N=115)$ & $p$ \\
\hline HSPM & & & $<0.001^{\mathrm{a}, \mathrm{c}}$ \\
\hline Negative & $224(97.4 \%)$ & $44(38.3 \%)$ & \\
\hline Positive & $6(2.6 \%)$ & $71(61.7 \%)$ & \\
\hline Median of the number of teeth with HSPM & $0(0-4)$ & $3(0-4)$ & $<0.001^{\mathrm{b}, \mathrm{c}}$ \\
\hline Distribution of the number of teeth with HSPM & & & $<0.001^{\mathrm{b}, \mathrm{c}}$ \\
\hline 0 & 224 (97.4\%) & $44(38.3 \%)$ & \\
\hline 1 & $1(0.4 \%)$ & - & \\
\hline 2 & $2(0.9 \%)$ & $4(3.5 \%)$ & \\
\hline 3 & $1(0.4 \%)$ & $17(14.8 \%)$ & \\
\hline 4 & $2(0.9 \%)$ & 50 (43.4\%) & \\
\hline MIH severity & & & - \\
\hline Mild & - & $34(29.6 \%)$ & \\
\hline Moderate & - & $12(10.4 \%)$ & \\
\hline Severe & - & $69(60.0 \%)$ & \\
\hline
\end{tabular}

Abbreviations: HSPM, hypomineralized second primary molars; MIH, molar incisor hypomineralization.

aPearson's chi-square test.

bMann-Whitney $U$ test.

cStatistically significant $(p<0.05)$.

Table 3 Comparison of teeth with HSPM

\begin{tabular}{|c|c|c|c|}
\hline Variables & Control group $(N=16)$ & Study group $(N=259)$ & $p$ \\
\hline \multicolumn{4}{|l|}{ Tooth type } \\
\hline 55 & $5(31.2 \%)$ & $68(26.3 \%)$ & $0.771^{\mathrm{a}}$ \\
\hline 65 & $5(31.2 \%)$ & $64(24.7 \%)$ & $0.558^{a}$ \\
\hline 75 & $3(18.8 \%)$ & $63(24.3 \%)$ & $0.769^{\circ}$ \\
\hline 85 & $3(18.8 \%)$ & $64(24.7 \%)$ & $0.768^{\circ}$ \\
\hline \multicolumn{4}{|l|}{ Demarcated opacity } \\
\hline Negative & $3(18.8 \%)$ & $62(23.9 \%)$ & $0.770^{\circ}$ \\
\hline White-cream & $13(81.2 \%)$ & $179(69.1 \%)$ & $0.406^{\circ}$ \\
\hline Yellow-brown & $0(0.0 \%)$ & $8(3.1 \%)$ & $1.000^{\mathrm{a}}$ \\
\hline White-cream + Yellow-brown & $0(0.0 \%)$ & $10(3.9 \%)$ & $1.000^{a}$ \\
\hline Atypical restoration & $2(12.5 \%)$ & 35 13.5\%) & $1.000^{\circ}$ \\
\hline Tooth extraction & $0(0.0 \%)$ & $42(16.2 \%)$ & $0.143^{\circ}$ \\
\hline \multicolumn{4}{|l|}{ The surface with demarcated opacity } \\
\hline Occlusal & $4(25.0 \%)$ & $126(48.6 \%)$ & $0.066^{\mathrm{b}}$ \\
\hline Buccal & $0(0.0 \%)$ & $22(8.5 \%)$ & $0.626^{a}$ \\
\hline Palatinal, lingual & $9(56.3 \%)$ & $99(38.2 \%)$ & $0.152^{b}$ \\
\hline Atypical caries & $1(6.3 \%)$ & $35(13.5 \%)$ & $0.703^{a}$ \\
\hline
\end{tabular}

Abbreviation: HSPM, hypomineralized second primary molars.

aFisher's exact test.

'Pearson's chi-squire test. 
Table 4 Distribution of HSPM in MIH subgroups

\begin{tabular}{|l|l|l|l|l|}
\hline Variables & Mild $(N=34)$ & Moderate $(N=12)$ & Severe $(N=69)$ & $p$ \\
\hline HSPM & & & & $0.039^{\mathrm{b}, \mathrm{d}}$ \\
\hline Negative & $7(20.6 \%)^{\mathrm{a}}$ & $6(50.0 \%)$ & $31(44.9 \%)^{\mathrm{a}}$ & \\
\hline Positive & $27(79.4 \%)^{\mathrm{a}}$ & $6(50.0 \%)$ & $38(55.1 \%)^{\mathrm{a}}$ & $0.147^{\mathrm{c}}$ \\
\hline Teeth number with HSPM & & & & $31(44.9 \%)$ \\
\hline 0 & $7(20.6 \%)$ & $6(50.0 \%)$ & $1(1.4 \%)$ & \\
\hline 2 & $3(8.8 \%)$ & $0(0.0 \%)$ & $10(14.5 \%)$ & \\
\hline 3 & $6(17.6 \%)$ & $1(8.3 \%)$ & $27(39.1 \%)$ & \\
\hline 4 & $18(52.9 \%)$ & $5(41.7 \%)$ & \\
\hline
\end{tabular}

Abbreviations: HSPM, hypomineralized second primary molars; MIH, molar incisor hypomineralization.

aThe difference between mild and severe MIH cases is statistically significant $(p=0.016)$

'Pearson's chi-square test.

cKruskal-Wallis test.

'Statistically significant $(p<0.05)$.

Table 5 Effects of MIH severity on HSPM rates

\begin{tabular}{|l|l|l|l|l|}
\hline & HSPM negative & HSPM positive & $\boldsymbol{P}$ & OR (\%95 CI) \\
\hline Severe & $31(70.5 \%)$ & $38(53.5 \%)$ & - & 1.000 \\
\hline Moderate & $6(13.6 \%)$ & $6(8.5 \%)$ & 0.745 & $0.816(0.239-2.783)$ \\
\hline Mild & $7(15.9 \%)$ & $27(38.0 \%)$ & $0.019^{\mathrm{a}}$ & $3.147(1.208-8.194)$ \\
\hline
\end{tabular}

Abbreviations: $\mathrm{Cl}$, confidence interval; HSPM, hypomineralized second primary molars; $\mathrm{MIH}$, molar incisor hypomineralization; OR, odds ratio. aStatistically significant $(p<0.05)$.

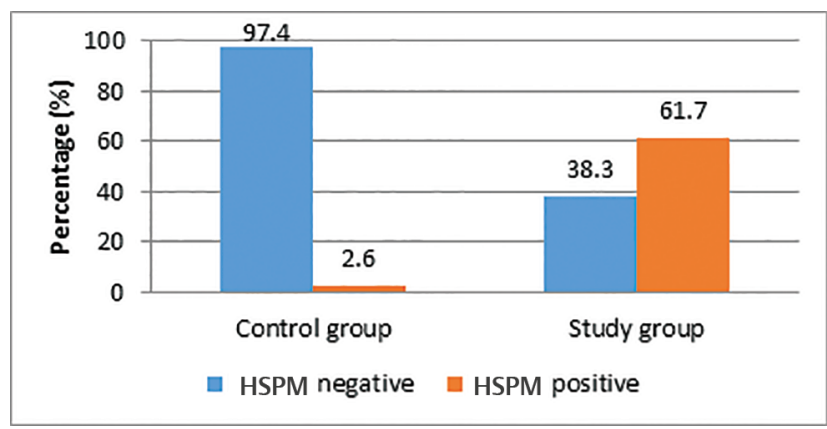

Fig. 4 The rate of hypomineralized second primary molars (HSPM) in the study and control groups.

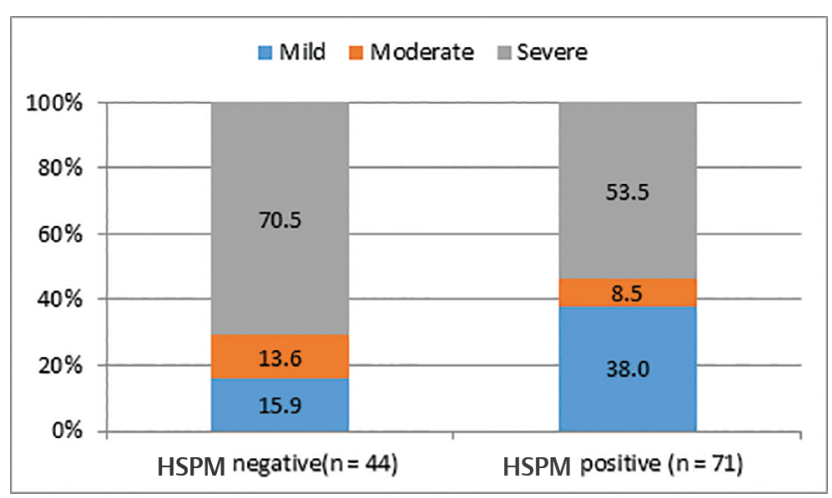

Fig. 5 Distribution of molar incisor hypomineralization (MIH) severity according to groups with and without hypomineralized second primary molars (HSPM).
Table 6 Demographical characteristics of the groups

\begin{tabular}{|c|l|l|l|}
\hline Variables & $\begin{array}{l}\text { Control group } \\
(N=230)\end{array}$ & $\begin{array}{l}\text { Study group } \\
(N=115)\end{array}$ & $p$ \\
\hline Age $(y)$ & $8(7-11)$ & $8(7-11)$ & $0.730^{\dagger}$ \\
\hline Age groups & & $0.447^{\dagger}$ \\
\hline 7 & $66(28.7 \%)$ & $32(27.8 \%)$ & \\
\hline 8 & $69(30.0 \%)$ & $36(31.3 \%)$ & \\
\hline 9 & $42(18.3 \%)$ & $33(28.7 \%)$ & \\
\hline 10 & $29(12.6 \%)$ & $11(9.6 \%)$ & \\
\hline 11 & $24(10.4 \%)$ & $3(2.6 \%)$ & \\
\hline Gender & & & $0.939 \ddagger$ \\
\hline Female & $117(50.9 \%)$ & $58(50.4 \%)$ & \\
\hline Male & $113(49.1 \%)$ & $57(49.6 \%)$ & \\
\hline
\end{tabular}

†Mann-Whiney $U$ test.

‘Pearson’s Ki-Kare test.

\section{Results}

The prevalence of HSPM increased in the study group (61.7\%) whereas it was $2.6 \%$ for control $(p<0.001)$ ( - Fig. 4 ).

The mean number of teeth with HSPM was significantly higher for the study group $(p<0.001)$. The distribution of the teeth number with HSPM was also found to be significantly different between the two groups $(p<0.001)(-$ Table 2$)$. 
The rate of MIH increased in children with HSPM when compared with children without HSPM (OR: 60.242, $p$ $<0.001$ ) ( Table 1). The analysis revealed that the risk of MIH development increased 3.558 times whereas the number of teeth with HSPM increased 1 point $(p<0.001)$ ( - Table 1 ). It was also observed that the risk of $\mathrm{MIH}$ development increases 6.788 times and 113.697 times whereas the number of teeth with HSPM is 1 to 2 and 3 to 4 when compared with children without HSPM, respectively $(p<0.001)$ ( - Table 1 ).

The distribution of teeth with HSPM, defect color, affected surface, atypical caries presence, atypical restoration, and tooth extraction $(p>0.05)$ ( - Table 3 ) revealed no significant difference between the two groups.

The rate of HSPM for the study group was significant in for each MIH subgroups in the study group ( $p=0.039$ ) (-Table 4). The rate of HSPM was increased in children with mild MIH compared with children with severe $\mathrm{MIH}$ $(p=0.016)$ (-Table 4). There was no significant difference between MIH subgroups in terms of the distribution of number of teeth with HSPM ( $p=0.147)$ ( - Table 4 ).

The relationship between the severity of MIH and HSPM was significant and the rate of HSPM was increased in children with mild MIH compared with the children with severe MIH ( $p=0.019)(\mathrm{OR}=3.147)$ (- Table 5). However, no significant difference was found between children with moderate and severe $\mathrm{MIH}$ in terms of the rate of HSPM $(p=0.745)$ (-Fig. 5).

There was no significant correlation between the number of teeth with HSPM and the severity of MIH when all subjects were assessed as single group $(r=0.164, p=0.081)$.

Mean age $(p=0.730)$, age distribution $(p=0.447)$, and gen$\operatorname{der}(p=0.939)$ showed no significant difference between the study and control groups (-Table 6 ).

\section{Discussion}

There are several epidemiological field studies investigating the prevalence of HSPM. ${ }^{19,24,27,28,35,36}$ The rate of HSPM was reported as 4.9 to $20.14 \%$ in these studies. Mittal and Sharma ${ }^{24}$ evaluated the prevalence of HSPM and MIH separately; they also reported that 18 out of 55 children with $\mathrm{MIH}$ (32.73\%) were having HSPM. Ghanim et $\mathrm{al}^{28}$ reported the HSPM and MIH association as 39.6\% in their study. However, our research presented a higher rate of HSPM compared with the abovementioned studies. This could be related to the study design where the present study was nonrandomized observational whereas others were field studies.

Our findings revealed a higher rate of HSPM when compared with the studies of Mittal and Sharma ${ }^{24}$ and Ghanim et $\mathrm{al}^{28}$ which can be related to the higher sample size of our study compared with studies mentioned above. Further observational studies with wider sample size are necessary for clarification regarding this matter. Also, the prevalence value found in the study group was higher than other studies which can be explained by the fact that the study was conducted on the selected patient population referred to our clinic. The prevalence of HSPM was found as similar to the field studies in the control group, as expected.
Elfrink et $\mathrm{al}^{20}$ first described the relationship between $\mathrm{MIH}$ and HSPM and reported that the risk of developing MIH is increased in children with HSPM and that the rate of developing MIH increases as the number of teeth with HSPM increases. Similar to this, our study showed that the risk of MIH development increased proportional to the number of teeth affected with HSPM. However, da Silva Figueiredo Sé et $\mathrm{al}^{37}$ found the number of affected primary teeth was not associated with the presence of MIH.

Several studies examining hypomineralization in primary teeth reported that the most common defect observed was demarcated opacities of enamel..$^{19,38-41}$ Elfrink et al $^{20}$ examined defects in children and reported that demarcated opacities was the most frequent (76.6\%) followed by the loss of enamel (31.9\%), atypical restorations (19.4\%), atypical caries (14.6\%), and extractions (11.2\%). Ghanim et a ${ }^{28}$ stated that the most frequently seen defect type was demarcated opacities followed by enamel loss while no atypical restoration was seen. Our finding showed the most frequent defect type was found to be demarcated opacities in children with HSPM in both groups and correlates with previous findings.

Considering the average age range of children, the psm of an 8-year-old patient have been functioning under the chewing forces for almost 5 to 6 years, it is inevitable for these teeth to be exposed to caries due to hypomineralization-related substance loss and inadequate protective treatments. Early caries should be the reason for timeless extraction which can explain the increased extraction rate presented in our study. Also, the lack of enamel destruction can be explained with masking of enamel destruction of atypical caries due to hypomineralization in these teeth, depending on the age range of the children.

Ghanim et $\mathrm{al}^{28}$ reported that maxillary psm were most frequently affected by HSPM, whereas according to Mittal and Sharma ${ }^{24}$ mandibular primary molars were most frequently affected. In this study, no significant difference was observed in terms of the influence of psm in both jaws in both groups among cases with HSPM.

Previous studies on HSPM assessed defect distributions in terms of surface, as well as in terms of tooth. ${ }^{24,28}$ Ghanim et $\mathrm{al}^{28}$ reported that the opacities were present on the buccal surface in general, whereas Mittal and Sharma ${ }^{24}$ reported that buccal and occlusal surfaces were equally the most frequently affected surfaces. Sidhu et $\mathrm{al}^{41}$ examined the lingual/palatal, occlusal/incisal, and buccal surfaces of teeth that clinically presented three surfaces excluding the mesial and distal surfaces. Their results revealed that the most commonly affected surface was the buccal surface. Unlike Sidhu et al, our study examined all five surfaces of the teeth and found that the opacities were generally present on the occlusal surface and palatal/lingual surfaces in the study group and control group, respectively.

Similar with the evaluation of MIH severity, the severity of hypomineralized psm with posteruptive fractions, atypical caries, atypical restoration, or extractions were also evaluated in HSPM cases..$^{20}$ Correspondingly, it was reported that the risk of developing MIH was more likely to occur in cases of mild HSPM rather than severe HSPM..$^{20,24,42,43}$ Our study 
found a relationship between two indicators whereas da Silva Figueiredo Sé et $\mathrm{al}^{37}$ observed no association between the severity of hypomineralization on primary teeth with the $\mathrm{MIH}$ development. Elfrink et $\mathrm{al}^{20}$ reported that the risk of $\mathrm{MIH}$ development in children with mild HSPM was higher than in children with severe HSPM. Although the severity HSPM cases were not assessed in this study, when the link between incidences of HSPM according to MIH severity was investigated, it was found that the risk of incidence of HSPM was significantly higher in children with mild MIH than in children with severe MIH. This finding may indicate that the factors causing the formation of defects are more likely to take place during perinatal and postnatal periods.

\section{Conclusion}

This study revealed that the incidence of HSPM in children affected with MIH is more likely to be seen compared with children without. In this regard, we think that HSPM may be a risk factor for MIH development. Hence, children with HSPM whose PFMs were not erupted, should be given extra attention for early diagnosing of $\mathrm{MIH}$, and these children should be followed up by pediatric dentists until the eruption of PFMs is completed. We believe that prospective studies in which the children with HSPM with a long-term follow-up will support knowledge presented in the literature.

\section{Conflict of Interest}

None declared.

\section{References}

1 Vargas-Ferreira F, Ardenghi TM. Developmental enamel defects and their impact on child oral health-related quality of life. Braz Oral Res 2011;25(6):531-537

2 Clarkson J. Review of terminology, classifications, and indices of developmental defects of enamel. Adv Dent Res 1989;3(2):104-109

3 Janković S, Ivanović M, Davidović B, Lecić J. Distribution and characteristics of molar-incisor hypomineralization. Vojnosanit Pregl 2014;71(8):730-734

4 Mathu-Muju K, Wright JT. Diagnosis and treatment of molar incisor hypomineralization. Compend Contin Educ Dent 2006;27(11):604-610, quiz 611

5 van Amerongen WE, Kreulen CM. Cheese molars: a pilot study of the etiology of hypocalcifications in first permanent molars. ASDC J Dent Child 1995;62(4):266-269

6 Weerheijm KL. Molar incisor hypomineralisation (MIH). Eur J Paediatr Dent 2003;4(3):114-120

7 Weerheijm KL, Groen HJ, Beentjes VE, Poorterman JH. Prevalence of cheese molars in eleven-year-old Dutch children. ASDC J Dent Child 2001;68(4):259-262, 229

8 Weerheijm KL, Jälevik B, Alaluusua S. Molar-incisor hypomineralisation. Caries Res 2001;35(5):390-391

9 Glodkowska N, Emerich K. Molar incisor hypomineralization: prevalence and severity among children from Northern Poland. Eur J Paediatr Dent 2019;20(1):59-66

10 Bullio Fragelli CM, Jeremias F, Feltrin de Souza J, Paschoal MA, de Cássia Loiola Cordeiro R, Santos-Pinto L. Longitudinal evaluation of the structural integrity of teeth affected by molar incisor hypomineralisation. Caries Res 2015;49(4):378-383
11 Jälevik B, Norén JG. Enamel hypomineralization of permanent first molars: a morphological study and survey of possible aetiological factors. Int J Paediatr Dent 2000;10(4):278-289

12 Suckling GW. Developmental defects of enamel-historical and present-day perspectives of their pathogenesis. Adv Dent Res 1989;3(2):87-94

13 Oliver K, Messer LB, Manton DJ, et al. Distribution and severity of molar hypomineralisation: trial of a new severity index. Int J Paediatr Dent 2014;24(2):131-151

14 Fagrell TG, Dietz W, Jälevik B, Norén JG. Chemical, mechanical and morphological properties of hypomineralized enamel of permanent first molars. Acta Odontol Scand 2010;68(4):215-222

15 Fearne J, Anderson P, Davis GR III. 3D X-ray microscopic study of the extent of variations in enamel density in first permanent molars with idiopathic enamel hypomineralisation. $\mathrm{Br}$ Dent J 2004;196(10):634-638, discussion 625

16 Farah RA, Swain MV, Drummond BK, Cook R, Atieh M. Mineral density of hypomineralised enamel. J Dent 2010;38(1):50-58

17 Weerheijm KL. Molar incisor hypomineralization (MIH): clinical presentation, aetiology and management. Dent Update 2004;31(1):9-12

18 Jälevik B. Prevalence and diagnosis of molar-incisor-hypomineralisation (MIH): a systemic review. Eur Arch Paediatr Dent 2010;11(2):59-64

19 Elfrink ME, Schuller AA, Weerheijm KL, Veerkamp JS. Hypomineralized second primary molars: prevalence data in Dutch 5-year-olds. Caries Res 2008;42(4):282-285

20 Elfrink ME, ten Cate JM, Jaddoe VW, Hofman A, Moll HA, Veerkamp JS. Deciduous molar hypomineralization and molar incisor hypomineralization. J Dent Res 2012;91(6):551-555

21 Ghanim A, Morgan M, Mariño R, Bailey D, Manton D. Molarincisor hypomineralisation: prevalence and defect characteristics in Iraqi children. Int J Paediatr Dent 2011;21(6): 413-421

22 Kühnisch J, Mach D, Thiering E, et al. GINI Plus 10 Study Group. Respiratory diseases are associated with molar-incisor hypomineralizations. Swiss Dent J 2014;124(3):286-293

23 Lygidakis NA. Treatment modalities in children with teeth affected by molar-incisor enamel hypomineralisation (MIH): a systematic review. Eur Arch Paediatr Dent 2010;11(2):65-74

24 Mittal N, Sharma BB. Hypomineralised second primary molars: prevalence, defect characteristics and possible association with molar incisor hypomineralisation in Indian children. Eur Arch Paediatr Dent 2015;16(6):441-447

25 Aine L, Backström MC, Mäki R, et al. Enamel defects in primary and permanent teeth of children born prematurely. J Oral Pathol Med 2000;29(8):403-409

26 Elfrink ME, Moll HA, Kiefte-de Jong JC, et al. Pre- and postnatal determinants of deciduous molar hypomineralisation in 6-year-old children. The generation $\mathrm{R}$ study. PLoS One 2014;9(7):e91057

27 Elfrink ME. Decidous Molar Hypomineralisation, Its Nature and Nurture. University of Amsterdam (UvA); 2012

28 Ghanim A, Manton D, Mariño R, Morgan M, Bailey D. Prevalence of demarcated hypomineralisation defects in second primary molars in Iraqi children. Int J Paediatr Dent 2013;23(1):48-55

29 Kusku OO, Caglar E, Sandalli N. The prevalence and aetiology of molar-incisor hypomineralisation in a group of children in Istanbul. Eur J Paediatr Dent 2008;9(3):139-144

30 Sonmez H, Yıldırım GTB. The prevalence and severity of molar incisor hypomineralization in a group of children living in Ankara, Turkey. Clinical Dentistry And Research 2012;37:35-41

31 Sönmez H, Yıldırım G, Bezgin T. Putative factors associated with molar incisor hypomineralisation: an epidemiological study. Eur Arch Paediatr Dent 2013;14(6):375-380

32 Kuscu OO, Caglar E, Aslan S, Durmusoglu E, Karademir A, Sandalli N. The prevalence of molar incisor hypomineralization 
$(\mathrm{MIH})$ in a group of children in a highly polluted urban region and a windfarm-green energy island. Int J Paediatr Dent 2009;19(3):176-185

33 Silva MJ, Scurrah KJ, Craig JM, Manton DJ, Kilpatrick N. Etiology of molar incisor hypomineralization - a systematic review. Community Dent Oral Epidemiol 2016;44(4):342-353

34 Elfrink ME, Schuller AA, Veerkamp JS. Poorterman JH, Moll HA, ten Cate BJ. Factors increasing the caries risk of second primary molars in 5-year-old Dutch children. Int J Paediatr Dent 2010;20(2):151-157

35 Costa-Silva CM, Paula JSD, Ambrosano GMB, Mialhe FL. Influence of deciduous molar hypomineralization on the development of molar-incisor hypomineralization. Braz J Oral Sci 2013;12:335-338

36 Meer Z, Almalki AY, Alasiri MA, et al. Prevalence of hypomineralization in second primary molars (HSPM) in 7 to 10 -year-old Saudi children. J Res Med Dent Sci 2020;8:124-127

37 da Silva Figueiredo Sé MJ, Ribeiro APD, Dos Santos-Pinto LAM, de Cassia Loiola Cordeiro R, Cabral RN, Leal SC. Are hypomineralized primary molars and canines associated with molar-incisor hypomineralization? Pediatr Dent 2017;39(7):445-449
38 Seow WK. Effects of preterm birth on oral growth and development. Aust Dent J 1997;42(2):85-91

39 Lunardelli SE, Peres MA. Prevalence and distribution of developmental enamel defects in the primary dentition of pre-school children. Braz Oral Res 2005;19(2):144-149

40 Slayton RL, Warren JJ, Kanellis MJ, Levy SM, Islam M. Prevalence of enamel hypoplasia and isolated opacities in the primary dentition. Pediatr Dent 2001;23(1):32-36

41 Sidhu N, Wang Y, Barrett E, Casas M. Prevalence and presentation patterns of enamel hypomineralisation (MIH and HSPM) among paediatric hospital dental patients in Toronto, Canada: a cross-sectional study. Eur Arch Paediatr Dent 2020;21(2):263-270

42 Negre-Barber A, Montiel-Company JM, Boronat-Catalá M, Catalá-Pizarro M, Almerich-Silla JM. Hypomineralized second primary molars as predictor of molar incisor hypomineralization. Sci Rep 2016;6:31929

43 Garot E, Denis A, Delbos Y, Manton D, Silva M, Rouas P. Are hypomineralised lesions on second primary molars (HSPM) a predictive sign of molar incisor hypomineralisation (MIH)? A systematic review and a meta-analysis. J Dent 2018;72:8-13 